\title{
Formulación de una política exterior: su dimensión política y social
}

\author{
Mariana Colottarmcolotta@usal.edu.ar \\ Universidad del Salvador \\ Julio Ramón Lascano y Vedia jlascano@usal.edu.ar \\ Universidad Católica Argentina
}

Recibido: 25/07/2020. Aceptado: 31/10/2020

Resumen: El tratamiento de la formulación de una política exterior constituye una deuda que tienen las ciencias sociales. El objetivo es plantear el análisis profundo de la dimensión política y social en su abordaje y un correcto diagnóstico global sobre el dinámico y crítico escenario mundial con los parámetros de realismo pragmático que requiere la economía, la sociedad y la política nacional e internacional. La formulación propuesta ha de ser bajo la elaboración académica y científica que exigen la Ciencia Política y las Relaciones Internacionales para convertirse en una herramienta de directa utilidad para quienes están a cargo de los mecanismos decisorios de política exterior.

Palabras clave: política exterior; diplomacia; relaciones internacionales; ciencias políticas; sociología; orden mundial

* Cómo citar este artículo: Colotta, M. y Lascano y Vedia, J. (2020). Formulación de una política exterior: su dimensión política y social. Relaciones Internacionales, 29(59), 109. https://doi.org/10.24215/23142766e109

Editor: Juan Alberto Rial, Instituto de Relaciones Internacionales Facultad de Ciencias Jurídicas y Sociales (Universidad Nacional de La Plata)
Entidad editora: Relaciones

Internacionales, es una publicación del Instituto de Relaciones Internacionales (Facultad de Ciencias Jurídicas y Sociales (Universidad Nacional de La Plata Argentina) https://r Vol 29 - no 59/2020

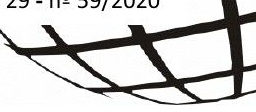




\title{
Foreign Policy Design: its Political and Social Dimension.
}

\section{Mariana Colotta1 y Julio Ramón Lascano y Vedia2}

\begin{abstract}
Foreign policy design is a debt that social sciences still have. Our objective in this work is to present a thorough analysis of its political and social dimension as well as a proper global assessment of the dynamic and critical world scenario based on the pragmatic realism parameters required by the economy, society and international and domestic politics. Our proposal will be carried out using the academic and scientific methodology belonging to both Political Science and International Relations, aiming to become a tool enjoying direct application by those in charge of foreign policy decision-making.
\end{abstract}

Key words: foreign policy; diplomacy; international relations; political science; sociology; global order.

1 Licenciada en Sociología (USAL, 1995), Especialista en Metodología de la Investigación Científica (UNLA, 2004), Doctora en Ciencia Política (USAL, 2010). Doctora en Ciencias de la Educación (2018

2 Embajador del Servicio Exterior de la Nación. Licenciado en Ciencias Políticas y Relaciones Internacionales de la Universidad Católica Argentina (1983). 


\section{El nuevo escenario internacional del siglo XXI. Post globalización y pos- modernismo}

Para realizar aportes útiles que conlleven a la formulación de una política exterior, es condición previa y necesaria analizar las condiciones y determinantes del escenario internacional contemporáneo, la dinámica misma de la sociedad internacional y sus impactos en las variables que hacen a la dimensión política y social de cada Estado.

La teoría política, el feminismo y el discurso posmoderno atraviesan las nuevas demandas políticas y sociales, y esto se traslada a los temas de agenda en las políticas públicas y los liderazgos sociales y políticos. El conflicto como base del ejercicio democrático, el desacuerdo, el poder y la inclusión de aquellos que no son parte constituyen la base de los reclamos sociales y políticos del siglo XXI.

La eficacia de la democracia operacional o efectiva (Pasquino, 2011) del debate posmoderno se pone sobre el tapete en la medida que garantice determinadas condiciones socioeconómicas, desigualdades contenidas y fecundas, el desarrollo estabilizador de la sociedad, el producto nacional bruto y la contabilidad de la riqueza en relación con la democracia gobernante. Tampoco pueden descuidarse la consolidación del régimen de vida democrático, la estabilidad y cultura política de la comunidad, las conductas de las elites, las capacidades de asociación y cohesión social, las lógicas mayoritarias y consensuales que se acuerdan en éstas, la estabilidad y flexibilidad del sistema, y, en definitiva, la posibilidad de establecer un modelo consensual que brinde lógica a la democracia.

El actual escenario internacional genera, a todo analista politólogo o sociólogo, gran desazón e insatisfacción general -no solo en tiempos de pandemia y crisis económica mundial. De modo estructural, son tiempos en que los países pobres y aquellos en vías de desarrollo no están en condiciones de aceptar tantos golpes derivados del nuevo desorden global. El desorden está instalado en las relaciones internacionales y es un multiplicador de caos, de injusticia y de hambruna mundial. Las potencias y países ricos del planeta -que representan el $85 \%$ del producto bruto global- no parecen estar preocupados por este quiebre multilateral que sufrió la cooperación internacional, en favor de este desorden de facto.

\section{2. Érase una vez el siglo XX...}

Sabemos que la Segunda post Guerra Mundial significó el primer cambio profundo del orden mundial contemporáneo. La desaparición del fascismo como modelo de desarrollo y autoritario fue perverso en la organización del Estado, su desarrollo económico y social moderno. Los Estados y sociedades derivaron en nuevos modelos para ese cambio, algunos considerados exclusivos en la guerra fría: un modelo de Estado autonominado liberal pero intervencionista y un modelo estalinista o de capitalismo de Estado.

Este mundo de ideas y fuerzas de carácter bipolar se basó en el equilibrio de poderes. $Y$ esto fue así desde el mismo nacimiento de los Estados, desde la generación de las teorías del Estado y las teorías del Poder. 
Las dos potencias del bipolarismo de la segunda postguerra son también dos modelos diferentes de organización económica y política para la solución de los conflictos sociales. Estados Unidos ejerció y actuó como líder del mundo libre occidental -con Europa de aliado- y la Unión Soviética comandó el mundo socialista, comunista y totalitario, con los países de Europa oriental, dominando a varios países desde la planificación estratégica central y universal. Se sumaron a estos modelos las colonias europeas en Africa y Asia. En América Latina, los países buscaron alianzas con los Estados Unidos, o amparo, y el modelo de mundo libre. En este nuevo orden geoestratégico Estados Unidos se convierte en un paíscontinente hegemónico y, de a poco, la mayor potencia que concentra más de la mitad de la producción industrial del mundo, se expande con espíritu de destino manifiesto, y genera una industria logística, militar y económica desarrollista, de carácter imperialista y tecnológico ilimitado.

Desde esta lógica de poder, los Estados Unidos ensanchan su expansión y se les permite asimilarse como aliados de este modelo capitalista a viejas glorias imperiales: Inglaterra, Francia, Alemania, Italia, Austria y el resto de la Europa que fuera subsumida en la guerra. América Latina juega, en general, la figura de acompañante de la surgida potencia unipolar que va ganado la carrera al comunismo.

Más allá de las fuertes expresiones del siglo XX contra el panamericanismo y los diversos intentos de autonomismo y hasta aislacionismo confundido a veces con neutralidad, en América, Estados Unidos encuentra como aliado estratégico a Brasil, con sus vaivenes de autonomía política y social.

América Latina en el siglo XX inicia su estado consciente de continente independiente y con capacidad de desarrollo autónomo. En varios momentos, sus líderes levantaron banderas nacionalistas y autonómicas, tal como lo hicieron Getulio Vargas o Juan Domingo Perón, desarrollismos nacionalistas que realizan su aporte propio al esquema de América Latina ansioso de presencia en el pasado siglo. Latinoamérica goza en ese momento de suficiente ímpetu de autonomismo característico del siglo XX con un alto grado de conciencia, que junto a otros conceptos desarrollistas del Uruguay, Chile y Colombia serán relevantes en la historia del continente y de su futuro (Sorj, Martuccelli, 2008).

La política de contención aplicada en la guerra fría fue diseñada y formulada por el diplomático y destacado politólogo, George Kennan ${ }^{3}$. Se propuso un modo de negociación de contención, desgaste y réplicas puntuales que aplicó los Estados Unidos a la Unión Soviética y satélites comunistas. Ello marcará la guerra fría y resultará ser un acierto en el diseño de la política exterior norteamericana, pues colabora con el posicionamiento de Estados Unidos. Esta política de contención fue un único y excepcional ejemplo de aplicación y ejecución de lineamientos de política exterior, producto de un correcto diagnóstico y óptimo diseño intelectual.

3“Policy Planning “(George Kenann, 1948) y “Memoirs 1925-1950” (George Kennan Boston Edit. Little Brown and Company en 1963 ) Kennan lo desarrolló y utilizó como plataforma de propuestas de política exterior en sus 17 obras. 
En las Relaciones Internacionales, el pasado siglo ligó fuertemente lo político a lo económico cuando avanzó el keynesianismo de la postguerra aplicado por Estados Unidos, con los países aliados y organismos económico-financieros. Sin lugar a dudas, se puede considerar como un elemento fundamental para las economías de los Estados que se desarrollaron en la segunda mitad del Siglo XX. Los Estados pasarían a ser los generadores de las economías industrializadas y piezas clave serían la economía, la bolsa, las finanzas y la nueva escala mundial de la industria y el comercio internacional. Recién en la década de 1970 emerge una crisis por parte del modelo keynessiano, desarrollista, benefactor e intervencionista. Sin embargo, reapareció con crudeza la tendencia liberal conservadora, durante la década de 1980. Las economías intervencionistas y liberales estarían basadas en el estudio directo de las características del mercado y del rol de los Estados, y ello sería aplicado a los medios de producción y a la acelerada aparición de la tecnología aplicada al crecimiento y al comercio internacional. La oferta y demanda en el mundo occidental principalmente, combinadas con la innovación tecnológica, desarrollarían en la economía y el comercio nuevos conceptos: calidad, crecimiento, productividad del trabajo, finanzas, inversiones, reglas regionales e internacionales.

En ese mundo unipolar, Estados Unidos logró posicionarse por economía, fuerza militar y estrategia, y también logró proveer a la lenta extinción del comunismo, que finalmente caería por sus propias contradicciones e ineficiencias. En ese mundo unipolar existió también un gigantesco abismo y desequilibrio entre la economía de Estados Unidos y el resto de los países y regiones del mundo. El industrialismo estatal estadounidense -la máquina industrial de guerra- y los avances tecnológicos surgidos de las carreras armamentistas, hasta los años setenta y ochenta, visualizaban a una potencia muy superior a lo previsto en todo lo que producción y comercio significara. Y también en el orden energético, tecnológico y militar.

Estados Unidos se convertiría en el primer proveedor para el consumo prácticamente mundial, capaz de financiar el desarrollo tecnológico y expandir bienes de consumo durable, nunca olvidando que el mecanismo utilizado estuvo directamente apuntalado por un enorme aparato de defensa militar. En los años de la guerra fría, la amenaza la representaría el comunismo patrocinado por la Unión Soviética. Los norteamericanos justificaron el mantenimiento de un gran aparato militar y la necesidad de acelerar la tecnología militar con propósitos persuasivos, que exigían grandes inversiones para producir innovaciones. Se generó así un complejo militar-industrial que permitió el crecimiento acelerado de las grandes corporaciones y la expansión de los bienes de consumo, consecuencia de la rivalidad entre los Estados nacionales que lideraban los dos bloques enfrentados en la guerra fría y de una manera de orientar la producción mediante el gasto del Estado.

Terminado el siglo, caído el comunismo y la cortina en 1989, las aspiraciones expansionistas de Estados Unidos y el mundo capitalista acompañado de un espíritu de cooperación internacional y los sistemas de ayuda financiera internacional, no alcanzarían para el desarrollo de los demás países esperanzados en este progreso indefinido. La globalización sería una ilusión y un mensaje utópico que chocó con los intereses capitalistas y del individualismo financiero mundial. 
Ello fue acompañado por un orden institucional nacido en 1945, impulsado por las potencias vencedoras; el esquema de organismos económicos internacionales diseñado en la Conferencia de Bretton Woods, New Hampshire. John Maynard Keynes había formulado para esta ocasión un esquema de ideas base que generaran estabilidad económica a los Estados de postguerra, que hasta entonces solo se habían apoyado en la ayuda directa del Plan Marshall. De esta manera, se crearían el Fondo Monetario Internacional (FMI) -base para el establecimiento de un Nuevo Sistema Monetario Internacional-y el Banco Mundial, destinado a la estabilidad, reconstrucción y fomento de las economías. Ello se completaría con los acuerdos comerciales que permitirían estabilizar balanzas de los países saneados, a través del General Agreementon Tariffs and Trade (GATT) y su sucesora, la Organización Mundial del Comercio (OMC), organismo económico que aún se debate en rondas con el objeto de avanzar en la liberalización del comercio internacional y el mejoramiento ético de las reglas de juego en este competitivo campo mundial.

En otro orden, el FMI -constituido por los bancos de los Estados- benefició a éstos con préstamos standby, supervisando el cumplimiento de los acuerdos y asegurando que los países mantuvieran políticas económicas con su sistema. Todos los países estarían sujetos a la disciplina fiscal y financiera del FMI. En los años ochenta, el FMI indiscutiblemente asumió un nuevo papel por auspiciar políticas neoliberales como respuesta directa a la crisis de la deuda externa y al estancamiento económico general que afectó prácticamente a todo el mundo, salvo algunos países de Asia. Los modelos económicos exclusivos de la postguerra llamados intervencionistas y keynessianos ingresaron en crisis en razón de las políticas liberales que impulsaron el Fondo y los organismos por exigencia de sociedades y gobiernos de países tenedores de deuda. El Banco Mundial o Banco Internacional de Reconstrucción y Fomento (BIRF) buscó inmediatamente desarrollar estrategias de liberación de mercados mundiales al igual que el FMI, claramente dominado por Estados Unidos hasta entrados los años setenta, y fue a partir de esa década que se incorporaron, parcialmente y en promociones desiguales, al control de estos organismos, los países industrializados.

Como puede verse, el pasado siglo XX encontró a los países de postguerra y en desarrollo en un esfuerzo por generar un sistema multilateral que garantizara orden y paz mundial, y esbozó un importante aparato burocrático que sirviera para la contención de conflictos en cada rincón del planeta. La base fue la cooperación multilateral. Superado por sus propias incapacidades y las fuerzas estratégicas y económicas de las grandes potencias, el sistema de Naciones Unidas fue jaqueado en su propia supervivencia. El sistema internacional de ayuda financiera fracasó con sus rígidas recetas en diversos Estados y sucumbió junto a grandes crisis financieras mundiales.

Hemos visto que la ortodoxia de recetas del FMI aplicadas en los ochenta y noventa fueron seriamente cuestionadas y desprestigiadas por sus resultados. La OMC nada pudo modificar en el mundo de las batallas comerciales, dumping y subsidios, convirtiéndose no solo en un generador de paneles mediadores, sino en otro tribunal internacional más de conflictos sin capacidad de generar soluciones globales; y esa misma suerte podría correr el Banco Mundial si el mundo no vuelve a plantarse reglas de juego justas en lo que ayuda financiera internacional hace. 
La supuesta globalización positiva marca el fin del pasado siglo, con la desesperanza de países en desarrollo y países pobres, que jamás alcanzaron el progreso de la paz norteamericana.

\section{Amanece el siglo XXI...}

El siglo XXI se presenta con un sistema multilateral debilitado, frágil y endeble, desconfiado profundamente de la globalización. La necesidad de restaurar un sistema de cooperación internacional es el signo de esta nueva era y el equilibrio de poder está reinstaurado.

Enormes procesos presupuestarios, técnicos y burocráticos abarrotaron los organismos, a lo que se sumó la multiplicación y validación de las ONGs. Las acciones unilaterales de los Estados, iniciativas regionales, acciones de diplomacia directa y de cumbre entre diversos Estados -agrupados a veces por categorías y otras por temáticas comunes- conformaron un conjunto que conllevó a desconfiar de la utilidad de los organismos internacionales.

La aparición repentina de la realpolitik ${ }^{4}$ del nuevo orden en un mundo dinámico conflictivo superó la inmovilidad y los resultados estériles de organismos, considerados como organismos utópicos en muchos casos. El presente siglo estará gobernado por Estados fuertes. Se inaugura un nuevo unipolarismo y una gobernanza desarrollada por diplomacia directa y de cumbres, como las que se dieron en Yalta ${ }^{5}$ y Postdam ${ }^{6}$ luego de la Segunda Guerra Mundial. Las decisiones más importantes son las que adoptarán el grupo de poderosos países denominado $\mathrm{G}^{7}$. Nuevos factores de poder que se generan para controlar y dar fórmulas superadoras a los organismos. Son los famosos grupos G: G5, G7, G11, G15, G20. De allí surgirán las pautas y lineamientos del presente ordenamiento global, lejano a un orden mundial.

Sin embargo, los organismos internacionales no se disuelven, más allá de perder credibilidad. Lejos de ello, se mantienen firmes en el escenario internacional, como legítima reserva del principio de la cooperación internacional. En el Sistema de Naciones Unidas, sus

\footnotetext{
4 Realpolitik es la política realista en alemán. Política o diplomacia basada en intereses prácticos y acciones concretas, sin atender a teorías o filosofías.

5Yalta: ciudad de Crimea donde ocurrió la Reunión Cumbre del 4 de febrero de 1945, antes de terminar la Segunda Guerra Mundial, entre los Jefes de Estado de la URSS, losiph Stalin; el Primer Ministro de Gran Bretaña, Winston Churchill; y el Presidente de Estados Unidos, Franklin Delano Roosvelt .

6 Posdtdam: ciudad cerca de Berlín donde se realizó en el Palacio Cecilienhof la Conferencia de Postdam entre el 17 de julio y el 2 de agosto de 1945, entre los líderes de la URSS (Iosiph Stalin), Gran Bretaña (Winston Churchill) y Estados Unidos (Harry Truman) para establecer el futuro de Alemania y el nuevo orden internacional al finalizar la Segunda Guerra Mundial.

7 G7: Grupo de los siete países del mundo de mayor peso político, económico y militar. Lo conforman Alemania, Canadá, Estados Unidos, Francia, Italia, Japón y el Reino Unido de Gran Bretaña. Fue fundado en Japón en 1973. Se ha sumado de observador la Unión Europea.
} 
propios desafíos y crisis la obligan a desarrollar objetivos sustentables en el Desarrollo, llamados ODS, y una agenda 2030 de 17 objetivos de desarrollo sustentable, que contemple el desarrollo en programas ciertos, busque trabajar en las injusticias económicas y sociales, y conforme programas para combatir la hambruna mundial. Naciones Unidas también aún deberá actuar en los casos de urgencias y emergencias que requieran la intervención de las fuerzas humanitarias de paz y en relación con otras acciones que hacen a la función de la organización mundial de la salud, los programas para la prevención y atención de catástrofes, el flagelo y las epidemias. Será aún el sistema de la ONU el que deba sostener y alimentar la agenda de Seguridad Internacional y desarme nuclear, en manos de la Organización Internacional de Energía Atómica y la Asamblea de desarme.

Un capítulo aparte lo merece la institucionalidad de la ONU, en la medida que tiene un propio valor histórico, jurídico y político internacional que debió ser fortalecido para una mayor eficacia en el cumplimiento de sus objetivos. La fuerza del Consejo de Seguridad y la Secretaría General construyeron las herramientas apropiadas a este efecto. El Consejo Económico y Social colaboró con las tareas que desarrollaron los Organismos Internacionales económicos y financieros que derivaron de las tareas permanentes del Consejo y sus resoluciones, sus reuniones y conferencias. Desde 1947 y hasta la actualidad, sus Fuerzas de Paz, interventoras en conflictos, pasaron de centenares de cascos azules a miles -se calculan 90.000 actualmente. Pudieron en su inicio pacificar parcial o casi totalmente crisis en Grecia, Israel-Egipto, Corea del Norte-Corea del Sur y el Canal de Suez. Luego avanzaron en el Medio Oriente, Líbano, Chipre, Mozambique, Somalía, Bosnia y Angola, durante sus guerras civiles hasta 2002. Sin embargo, mostraron dificultades y fracasos, como lo señala la misma página oficial de las fuerzas de la ONU en casos muy complejos con manejos inapropiados, como en el caso de Ruanda en 1994 y Haití en 2007.

En general puede aseverarse qué si no existieran los cascos azules; muchas de estas crisis pudieran haberse expandido en peores o más amplias guerras que hoy completarían el que llamamos cuadro de "guerras permanentes "que el mundo vive hasta el día de hoy.

El multilateralismo del siglo XX, que asomó desde la descolonización y el crecimiento industrial y tecnológico desarrollado por los países industrializados en ese centenio, permitió institucionalizar más problemáticas del mundo existente y del mundo pobre. Y por ello se fue conformando un sistema de multilateralismo y cooperación internacional que dio a paso a la conformación y accionar de los organismos internacionales, que por sus resultados son visualizados como valiosos, aunque contrariadamente en otras oportunidades se los vea como innecesarios, al menos en su dimensión de costos y burocracias.

En lo que hace a la salud mundial, la OMS generó el Fondo Global de Salud y la concientización de la problemática de la salud pública. Sin embargo, la OMS actualmente está en jaque. Muestra una conducción mundial débil ante las graves circunstancias y pandemia mundial. La OMS es un organismo que debe ocuparse de un sistema de información, de regulación y de rápida acción ante las epidemias y pandemias que afligen a la humanidad, en especial a su tercio más pobre y sin esperanzas. Podemos pensar cuánto peor estaría sufriendo la humanidad ante estos graves problemas globales de salud si la OMS no tuviera existencia y presupuesto. Aunque en la actualidad, debería ser el organismo primario y eficiente de mayor presupuesto y prestigio, no lo es. La burocracia e ineficiencia lo desdibujan 
Además estár sospechado por activo en negocios y comercio con los laboratorios mundiales. Su comercialización oligopólica ocupa la agenda de salud mundial. Será difícil pensar hacia el futuro con una OMS que se maneje con esta estructura y accionar sin objetivos ni tareas exitosas.

La $\mathrm{FAO}^{8}$, que incluye y comparte su agenda con el $\mathrm{FIDA}^{9}$ y con el Programa Mundial de Alimentos (PMA), constituyen programas de estudio ciertos, atendiendo a la agricultura y la seguridad alimentaria, temática primaria en la nueva agenda global. Además de distribuir alimentos para proyectos de desarrollo, refugiados de larga duración y personas desplazadas; y proporcionar comida de emergencia en casos de emergencias y desastres naturales, la FAO soporta las presiones de organismos, fundaciones y acuerdos comerciales que solo priorizan la escasez de alimentos como un gran negocio. Los trabajos y dedicación de los agentes de la FAO y sus representaciones diplomáticas son útiles y proactivos, eficientes en sus programas.

También el ACNUR (Alto Comisionado de Naciones Unidas para los Refugiados), dedicado con nunca suficientes recursos a los refugiados, afronta una intensa agenda de contención, sostenimiento, alimentación y emergencias de miles de personas que la humanidad destierra y empuja a migrar por problemas económicos, laborales, sociales, de salud y obviamente de guerras. Todo ello con bajos presupuestos y una necesidad de mayor concientización.

Por último, destacamos la OIEA ${ }^{10}$, abocada al problema de la energía en el planeta, el desarme y asuntos nucleares, que merece un espacio de reconocimiento pasado y presente. El organismo es proactivo y es el guardián activo de la seguridad y la paz mundial, ejecutivo de una nueva Conferencia mundial en la materia que nos debemos globalmente.

Estos son los organismos vitales en la actualidad, los que cubren nuestra agenda global urgente: seguridad internacional, medio ambiente y cambio climático, seguridad alimentaria, refugiados y migraciones, y hambruna mundial. Los demás debieran revisarse en sus costos y utilidades. Así lo ve la comunidad mundial y el practicismo debe aplicarse en esta cuestión global contemporánea.

El sistema multilateral y la cooperación por organismo no escapan aún de la desilusión y el fracaso. El mundo deja atrás el bipolarismo del siglo XX al no existir el enfrentamiento de dos potencias rivales en modo amenaza de guerra total. Sólo Estados Unidos es el referente del nuevo equilibrio de poder, que ya no asiste a la reconstrucción del sistema de cooperación internacional más justo. China compite de manera fuerte y provocadora desde un punto de vista comercial y compromete a Estados Unidos y al comercio mundial, uunque

8 FAO: Con sede en Roma, es la Organización de Naciones Unidas para la Alimentación y la Agricultura con la función principal de erradicar el hambre en el mundo. Cuenta con 197 miembros al año 2013.

9 FIDA: Con sede en Roma, es el Fondo Internacional de Desarrollo Agrícola, agencia especializada de las Naciones Unidas cuyo objetivo es movilizar recursos adicionales para promover progreso económico de habitantes pobres de zonas rurales y mejorar la productividad agrícola

10 OIEA: Organismo Internacional de Energía Atómica perteneciente al sistema de Naciones Unidas con sede en Viena, Austria. 
la batalla no es solo comercial sino profundamente política. China detenta graves límites propios del régimen político socialista centralizado y de partido único, que posterga libertades y derechos humanos primarios. Rusia renace como país y se expande en su influencia territorial y económica, resurgiendo de a poco de las cenizas que dejó el comunismo.

Pero solo Estados Unidos posee la concentración de poder estratégico, militar y logístico con llegada y contención en todo el planeta, además de los recursos materiales, económicos y tecnológicos para mantener este poder unipolar centralizado. Es un mundo que asiste a una guerra permanente abierta -no bipolar- y tecnológica. La estética de la guerra es diferente a la de otras épocas; no hay uniformes ni banderas, y los drones reemplazan gigantescas ecuaciones militares. En silencio, arteramente.

Además, la televisión y medios digitales dominan parcialmente la tecnología de punta para llegar a mostrar amenazas de guerras, bombardeos y guerras. Nos vamos enterando por medio de las amenazas norcoreanas o de las peligrosas actitudes de Irán. Leemos sobre el equilibrio en Medio Oriente que pende de frágiles alianzas. Los desastres producidos por las migraciones y los refugiados superan a la misma Unión Europea. Y el ACNUR también se ve superado en varios niveles en la cuestión migratoria y de refugios.

El panorama europeo es de ebullición: Europa convive con la xenofobia, los nacionalismos y los separatismos crecientes. Y aún está sin rumbo en su estabilidad económico comercial, sobre todo, a partir de la dura salida de Gran Bretaña por el Brexit en 2020. Como la historia indica, los británicos no tendrán seguramente problemas en afrontar su nueva instancia de alianzas con sus socios históricos de su propio mercado, sumando a los Estados Unidos, como paraguas protector principal de esta política. Ni tampoco serían graves las dificultades de ordenamiento interno y externo con Irlanda o Escocia.

A esta contextualización se suma la debilidad de la OTAN y la distribución de fuerzas a nuevos objetivos en Oriente, Medio Oriente y otros países y mercados, que acompañan este nuevo equilibrio del poder. La debilidad de los organismos internacionales para imponer medidas correctoras o establecer un orden, especialmente entre los poderosos, ha sido también responsable de ello. Ni el G20 ni el G7, constituido en 1975, ni la OCDE, foros y organismos creados para combatir políticas nacionales aplicadas al comercio mundial y el proteccionismo, demuestran ser exactamente soluciones concretas para el nuevo orden requerido.

Estados Unidos acentúa su desprecio por las políticas propuestas orgánicamente por organismos internacionales, incluídos los comerciales, como los de la OMC. Tampoco acepta la existencia misma de un ente ordenador institucional y menos regulador, como éste. Luego de la Reunión de OMC de Buenos Aires en 2017 y la Cumbre del G20 en 2018, el Presidente de Estados Unidos, Donald Trump, agrega en particular formatos de conducción de política exterior anti-cumbre y anti-organismos, anuncios bilaterales de proteccionismo dirigidos primariamente a China, pero como señalamiento general al sistema internacional.

Henry Kissinger, décadas antes, ya había reclamado estas conductas de manera histórica; sobre todo, cuando señalaba que para la consideración de todo nuevo orden debe pensarse primero como base para reforzar los intereses nacionales norteamericanos; haciendo explícita su tesis sobre la política realista e imperial: "Tanto las disputas como las amenazas 
de tendrían que ser evaluadas casi exclusivamente pensando en el equilibrio del poder" (1994).

Las contradicciones internas y las políticas de planificación partidarias estatales en el gigante chino permanecen intactas y no admiten las rebeliones de Hong Kong ni territorios vecinos que quieran revelarse a esa planificación comunista, que aún existe, a pesar de los cambios culturales neocapitalistas que han acontecido y son tan difundidos. Para creer en tales modelos comunistas devenidos capitalistas y abrazar alianzas más fuertes y creíbles, es necesario estudiar otras alternativas de países aliados con mejor construcción de regímenes políticos y relacionamiento externo que sean de interés a nuestro crecimiento comercial, sin importar las ecuaciones políticas, por ejemplo, Vietnam.

Los Estados Unidos vuelven a defender su proteccionismo primario a efectos de reconfirmar su poder unipolar en base a la defensa de sus intereses nacionales, haciendo prescindibles acuerdos con su viejo aliado europeo, al que confrontan coyunturalmente con la expansión de las economías de China y Oriente. Estados Unidos conduce de modo unipolar, con estrategias clásicas de amenazas y marcando diferencias en su relación con el mundo de Oriente y Medio Oriente.

El mundo pasa a estar envuelto en el siglo XXI en una guerra comercial, preeminentemente política, impuesta por Estados Unidos y China. Todo ello, sumado a la desestabilización de los demás Estados cuyos mercados son afectados tanto en Europa como el mismo Sudeste Asiático. La dimensión política y social de Estados Unidos marca su derrotero en pandemias, políticas internas y externas, y afecta a todos los Estados y organismos que pretendan confrontar este unipolarismo.

\section{América Latina, la integración regional y las políticas exteriores}

América Latina es un continente joven, conquistado y colonizado bajo una institucionalidad y normativas europeas provenientes de norte a norte, sajones en el caso norteamericano, y de pautas latinas y cristianas para el centro y sur del continente. Los ciudadanos de esta América Latina absorbieron esquemas institucionales para la construcción de sus Estados, la búsqueda de sus normativas de convivencia y cohesión social, la frágil administración de sus riquezas y el asentamiento de sus regímenes políticos, clases dominantes y demás estadios ciudadanos. Decidieron independizarse del continente europeo y lanzarse a la independencia y crecer como Estados independientes.

El distinguido politólogo Marcelo Cavarozzi en su libro La construcción política de las sociedades latinoamericanas y su talón de Aquiles: el régimen político (2014) nos señala el importante desafío que debieron enfrentar las elites de América Latina:

Dirigieron el proceso de plena integración al mercado mundial, debieron también promover la construcción de Estado, es decir la creación de mecanismos burocrático, jurídicos, hacendarios, militares y de reproducción cultural que les permitieran ejercer un cierto control, más o menos efectivo, sobre la población y territorio. 
Es de imaginar, como nos clarifica Cavarozzi, que América Latina fue prácticamente diseñada a partir de la traslación de un modelo de matriz Estado-céntrica con funcionamiento desarrollista $y$, a veces, industrializador. El continente afronta hasta la fecha la tarea de asentarse institucionalmente, definir los roles de sus Estados, dirimir sus conflictividades de historia, regímenes políticos y estatus de cohesión social, lo que claramente aún le pesa.

Este presente encuentra a algunos países de América Latina como víctimas de problemas institucionales muy serios. Muchos de ellos son históricos y estructurales, como las rebeliones sucedidas en 2019 y 2020 en Chile. Estas son manifestaciones explosivas esperadas y heredadas de antiguas estructuras sociales pactadas tres generaciones atrás, como el caso de continuas protestas en estos años en Ecuador, que no puede aún sostener fronteras y autonomía propia, ni en lo institucional ni en lo financiero/monetario, mostrándose frágil en el paisaje continental. O como el caso de Colombia, que a fines de 2019 y 2020 sufre manifestaciones y protestas contra el Gobierno, en atención a las insatisfacciones económicas y sociales de regímenes que aparecen como no representativos ni comprensivos en las problemáticas reclamadas. Más claro aún fue el golpe de estado en Bolivia a fin de 2019, que ha mostrado a las claras la conjunción perfecta del vínculo entre la política interna partidaria e institucional y la política exterior y comercial, pendiente del enfrentamiento por las reservas de litio.

No son conflagraciones alineadas por un imperio externo. Están en una misma línea temporal y responden a su peculiar diseño interno y política exterior, o bien a la falta de un diseño internacional. Todo un desafío al momento de diseñarse una política exterior en el ámbito regional.

La integración regional es un mandato histórico y un objetivo permanente que aparece en medio de la ardua tarea que resulta generar en América Latina sus necesidades de crecimiento. Al respecto la estudiosa del Mercosur, Mariana Botto (2015) lo analiza de manera comparada y ratifica esta peculiaridad de América Latina con su continua vocación integradora -que lo coloca como el continente con más cantidad de proyectos de integración diseñados y muchos de ellos consolidados- ejemplificado en el mismo Mercosur.

Los fracasos en la institucionalidad de América Latina deben ser alarmas permanentes en los analistas internacionales y politólogos. La OEA, convertida en dependencia de Washington, gusta a algunas visiones conservadoras y ofende a la mayoría de líderes y pensadores de América Latina. Los fracasos o tardías políticas de OEA en este siglo son graves. En el caso del golpe de Estado a Bolivia de 2019, quedó develado este espíritu no consensuado sobre intervencionismo y golpes de Estado más o menos aceptados. La OEA, como consenso organizacional con Washington, pudo al principio y por espíritu regional fomentar la generación de organismos regionales para favorecer a los países de la región. Es el contexto y lectura de informes del SELA o la CEPAL con recomendaciones y estudios, investigaciones económicas (nunca exitosas) que ofrecieron y ofrecen a los distintos gobiernos regionales. Asimismo, desde la OEA se impulsaron muchos de los organismos de integración de la región, como el Pacto Andino, el Acuerdo de libre Comercio NAFTA, la Asociación Latinoamericana de Libre Comercio (Aladi), el Mercado Común del Sur de América (MERCOSUR), la Comunidad Sudamericana de Naciones (UNASUR) y la Alianza del Pacífico y la Comunidad de Estados Latinoamericanos y Caribeños (CELAC). 
Si bien UNASUR aparece inactiva, este particular organismo contempló la cúspide más alta en la búsqueda de una Comunidad Sudamericana de Naciones, intentando integrar proyectos físicos y de infraestructura, energía, minería, asuntos de defensa y los foros civiles de las sociedades de la región. La falta de coordinación de políticas económicas nacionales y los protagonismos no colaboraron en la mayor proyección del organismo, creado con objetivos certeros, finalmente no conducidos a objetivos concretos.

Deben destacarse en el funcionamiento regional, el Mercosur y la Aladi. En ellos se concentra el mayor porcentaje de la agenda comercial y de integración del Mercosur, así como la confección y gerenciamiento de los acuerdos de complementación económica (ACE), acuerdos comerciales regionales y propuestas de convenios sectoriales. El MERCOSUR, generado desde las Cancillerías de Argentina y Brasil, y sus verdaderos formuladores intelectuales, se mantiene con éxito y se institucionalizó mostrando que las voluntades políticas de sus cuatro países fundadores han sido la clave de su permanencia y buen funcionamiento aduanero, canalización comercial y foro de acuerdos institucionales intra-miembros. Logró la atención y comercio de Chile y Bolivia, como logró ser el organismo lógico para avanzar en la expansión de la subregión en convenios con la Unión Europea y el EFTA -Comunidad de países no miembros de la Unión Europea, que son Islandia, Liechestein, Noruega y Suiza-, y el programa de relacionamiento externo. La subsistencia, la ecuación estratégica y principal alianza de Argentina con Brasil, como la causa de Malvinas y las necesidades comerciales del país, refuerzan al Mercosur como punto de salida y retorno en toda la política exterior.

La dimensión política y social de América Latina se profundiza cuando hablamos de la tercera ola democrática que renueva el debate acerca de cómo se organizan nuestras sociedades para responder a un contexto internacional fuertemente global y altamente competitivo en el continente con mayor nivel de exclusión del mundo. En esta región los populismos se caracterizan por un fuerte liderazgo que propone fundamentalmente un cambio en las relaciones de poder en la sociedad y plantea una reinstalación de la primacía de lo político por sobre lo económico, un rol más comprometido del Estado en el desarrollo, no sólo de políticas públicas sino una mayor regulación de los mercados donde se establezca otra dinámica entre las relaciones de fuerza y de poder. En este proceso, por el que atravesaron la mayoría de los países de la región después de la crisis de 2001, es donde se puede vislumbrar un cambio de paradigma que se contrapone fuertemente en los ochenta y noventa, y que intenta integrar al debate democrático a nuevos actores políticos, colectivos que puedan ser incluidos en la discusión por la distribución del poder y de la riqueza.

Laclau (2005), centrándose en la articulación entre las instituciones democráticas y la movilización de masas, reflexiona sobre el populismo desde la lógica de articulación de las demandas sociales de una parte del pueblo (plebs) que erige su demanda como la de la comunidad política toda (populus), desde un sentido positivo, despegándolo de una ideolo- 
gía demagógica o nacional -popular y autoritaria asociada a los populismos étnicos europeos. ${ }^{11}$ En ese contexto, las dificultades eran muchas en la relación inclusión-capitalismo global, y muy difícil de modificar algo en esta relación cuando básicamente se habla de lo poco que la política tiene para ofrecer o para cambiar la realidad.

Los pueblos latinoamericanos han reaccionado en forma homogénea en casi todos los países del continente en la búsqueda de un cambio profundo. En aquellos países donde había un sistema político que funcionaba, con partidos políticos de peso, la mayoría de la sociedad optó por nuevas fórmulas políticas de izquierda, caso de Brasil con Lula y de Uruguay con el Frente Amplio de Tabaré Vázquez. Piénsese que el único modelo de izquierda real vivido en el Uruguay moderno contemporáneo lo acaparó la Presidencia de José Pepe Mujica, y Tabaré Vázquez lo sucedió en un mismo esquema político partidario. No obstante ello, las tradiciones democráticas del Uruguay han sido distintivas y más fuertes, y permitieron a Tavaré evadir el populismo y gravar su gestión como progresista con sesgos conservadores.

Estos líderes formarían parte de uno de los tipos de proyectos de base populistas que se iniciaron en la región. En los países con tradición de partidos políticos con legitimidad y consenso en la opinión pública, la mayoría adhirió a nuevos proyectos, al avance de fuerzas progresistas que se diferenciaban de aquellos más conservadores propuestos por la derecha. La otra vía de la izquierda se dio en aquellos países donde se produjeron cambios críticos donde no sólo cayo un sistema económico, sino que esta caída también arraso con el sistema de partidos y a las elites gobernantes. Así surgieron actores emergentes y líderes que básicamente buscaron reconstruir el Estado y los lazos entre el Estado y la sociedad. Es el caso de Venezuela, Ecuador y Bolivia y, en parte, el gobierno de Lugo en Paraguay y un poco más moderado en Argentina, donde el peronismo nacionalista siempre ha compensado los gobiernos autonominados como populistas progresistas.

La izquierda en la América Latina de los años 2000 evidenciaba dos modelos en la región: el de Hugo Chávez, populista, antiliberal, estatista y antinorteamericano; y el de Ricardo Lagos, moderado y favorable al libre mercado, al fortalecimiento de la democracia liberal y a la integración con el mundo desarrollado. Se daba, entonces, por un lado, una izquierda socialdemócrata y previsible, como la chilena y la de algunos otros países; y, por otro, la más mestiza, indígena y populista, como la de Ecuador, Venezuela y Bolivia, mientras que a la Argentina de Kirchner la ubicaban en punto intermedio ${ }^{12}$.

11Ferrás G. (2018), “Pensar el pueblo. Populismo y tradición democrática en América Latina.” UBA-Instituto de Investigación Gino Germani. Ponencia preparada para el XXXVI Congreso Internacional Latin American Studies Association. Barcelona. España.

12Como explicaba Noravo (2006), Kirchner buscaba satisfacer a chavistas y moderados, y neutralizar a potenciales competidores de ambas orientaciones. Pero este objetivo lo logra sólo en parte: los rasgos que permiten identificar al kirchnerismo como un populismo moderado, capaz de equilibrar y componer tendencias opuestas en el terreno económico, institucional o de política exterior son los mismos que le imponen límites a su capacidad de innovación y ofrecen oportunidades para la crítica. Acceso deshabilitado: http://kirchner\%2c+la+izquierda+y+el+populismo\&d=4853830200928667\&mkt=es-AR\&setlang=es-

ES\&w=qjyGv_maRi6fRHx7zXM6rg8lvp13sYPk. (5 de agosto de 2018). 
Justamente, le debemos a Marcelo Cavarozzi (2014) el análisis de estos tiempos y fenómenos en términos sociológicos. Durante el último cuarto de siglo XX, se produjeron cambios significativos en las sociedades de América Latina. Estos cambios estuvieron fundamentalmente vinculados a la desarticulación del modelo prevaleciente hasta la década de 1970 y, por ende, fueron de índole destructiva. Al principio pudo no percibirse la destrucción, por el optimismo surgido de diagnósticos contemporáneos. Pero avanzando en los ochenta y los noventa, éstas fueron concebidas por sus protagonistas y sus etapas fundacionales de democracias más estables, y luego de economías de mercado libradas del artificio del Estado. Esta ilusión de una "primavera democrática" y de un "paraíso de mercado" se disipó luego, tarde o temprano. La ilusión democrática sucumbió con las hiperinflaciones que entre 1985 y 1990 azotaron a Bolivia, Argentina, Brasil y Perú, y un poco menos a México, Uruguay y Venezuela. El paraíso del mercado probó ser así un espejismo que resultó opacado por el efecto tequila de 1994-95 y fue definitivamente borrado por la crisis mundial desatada a partir de 1997-98.

Entre 1999 y 2004 se produjo una serie de quiebres democráticos y políticos que fueron más allá de la alternancia de partidos en los gobiernos de América Latina que habían ocurrido y sucedido en los años ochenta. Muchos países agotaron sus sistemas de partidos políticos (Venezuela, Perú, Colombia). La Argentina terminó su bipartidismo. Pero emergieron liderazgos en otros países, como el de Lula en Brasil y Evo Morales en Bolivia, que fueron representantes de las clases más postergadas en ese momento. Evo y Lula, líderes populistas, se presentaron como la encarnación del pueblo, enfrentando las oligarquías y los poderes imperiales y especialmente a los Estados Unidos. Estos líderes rechazaron todo formulismo neoliberal y también rechazaron todo tipo de esquema democrático clásico de partidos. No extinguieron la democracia electoral, pero la subordinaron a los liderazgos cesaristas (Cavarozzi, 2014).

América Latina, en este contexto, decididamente no fue foco de atención de una política por parte de los Estados Unidos. Este país envió algunas señales positivas a su aliado estratégico Brasil, advirtiéndole sobre la necesidad de no involucrarse en los que considera conflictos de su jurisdicción: Venezuela, Cuba y Nicaragua. Y reparos para Bolivia, afectada en 2019 por un golpe de estado bañado de problemáticas internas electorales y políticas económicas que batallaron por conservar sus intereses en la industria del litio. Argentina, Chile o Uruguay dejaron, desde varios años atrás, de estar en el centro estratégico de análisis, pudiendo o no ser aliados de este nuevo intento de orden por poder. Tenemos, como subcontinente, una gran oportunidad.

\section{Cooperación internacional y solidaridad vs equilibrio de poder. La nece- sidad de la formulación de una política exterior nacional con atención a la agenda política y social contemporánea.}

Está claro que la globalización, cuestionada por sus fracasados resultados en el progreso del crecimiento y desarrollo de los países pobres y en vías de desarrollo, se convirtió en uno de los principales problemas de análisis de las Relaciones Internacionales contemporáneas. 
Pensar en un nuevo orden mundial sin pensar en cómo compensar los fracasos mencionados y desarrollar la agenda global que el mundo necesita requiere de dimensiones políticas y sociales, además de los instrumentos de formulación adecuados. Pensar en una nueva agenda global también es el mandato que tiene las Naciones Unidas. El planeta debe alentar liderazgos y regímenes democráticos que promuevan la cooperación y esta agenda inclusiva: generación de acuerdos de seguridad internacional en conferencias de desarme, promoción de tecnologías para combatir terrorismos fundamentalistas, intervención humanitaria en conflictos y nuevas guerras, impulso a la agenda 2030 de desarrollo sustentable, combate contra la hambruna mundial, atención al refugio de los millones de migrantes sin destino, y refuerzo de los programas de derechos humanos y de género en todos los niveles.

Relevante resulta la incorporación de la perspectiva de género, como tema de debate posmoderno y resultado de un largo proceso social y político. En las últimas décadas del siglo XX y particularmente en el contexto latinoamericano, el concepto de género paulatinamente fue formalmente visibilizado en los estatutos legales de diferentes países de la región. Esta institucionalización del enfoque de género ha significado la inclusión de un nuevo paradigma en lo referente a las políticas públicas.

En el marco del debate en torno al papel del Estado, en relación con la equidad de oportunidades entre mujeres y varones, cobra una gran importancia la idea de llevar adelante acciones y procesos que conlleven transformaciones y cambios en los patrones culturales, políticos y administrativos. Para ello el marco jurídico del gobierno local, provincial y nacional (carta orgánica y normativas), las declaraciones, convenciones y documentación emanadas de organismos internacionales ayudan a la visibilización de la problemática de género y a la construcción de una agenda. Las estrategias desplegadas a tal fin deben transformar roles y flexibilizar estereotipos, reestructurar las relaciones de poder, generar un nuevo modelo de desarrollo, integrar la perspectiva de género a los procesos de planificación del desarrollo de manera estructural, buscar organicidad y sustentabilidad.

El primer instrumento internacional de Derechos Humanos en ocuparse de la temática, fue la "Convención sobre la Eliminación de Todas las Formas de Discriminación contra la Mujer" (CEDAW), aprobada en 1979 por la Asamblea de ONU. La Constitución Argentina, luego de la reforma realizada en el año 1994, expresa en su art. 75 inciso 22 que los tratados internacionales de derechos humanos tienen jerarquía constitucional. Además, la "Convención Interamericana para Prevenir, Sancionar y Erradicar la Violencia contra la Mujer", la Convención de "Belém do Pará", fue aprobada por la Asamblea General de la Organización de Estados Americanos, el 9 de junio de 1994, ratificada por Argentina a través de la Ley 24.632 del año 1996. Este instrumento establece, en su art. 3o, el derecho de toda mujer a vivir una vida libre de violencia, tanto en el ámbito público como privado. En Argentina, la aprobación de la Ley 26.485 en abril del año 2009 "para prevenir, sancionar y erradicar la violencia contra las mujeres en todos los ámbitos donde desarrollan sus relaciones interpersonales", significó un avance en la concepción y orientación para el abordaje integral y la lucha contra la violencia hacia las mujeres. Esta propone superar una vieja mirada asentada en el abordaje de la violencia contra las mujeres como familiar o doméstica.

En cuanto a los avances más recientes, podemos mencionar: la "Ley de paridad de género en ámbitos de representación política" (2019), la "Ley de cupo sindical”, la "Ley de 
protección integral a las mujeres" y la reglamentación de la licencia laboral por violencia de género. En cuanto al sector privado, las iniciativas actuales apuntan hacia el Homeoffice Flexibilidad, Mentoreo, Extensión de licencias por maternidad, Cupo de mujeres en cargos directivos, CV ciego, Guarderías - lactarios y equidad salarial.

Una nueva agenda de política exterior no puede obviar la perspectiva de género. A nivel mundial, la presencia de las mujeres en puestos de liderazgo sigue mostrando una brecha respecto de los varones y el ámbito de la diplomacia no constituye una excepción. Pese a que en los servicios diplomáticos la presencia de mujeres con rango de Embajadoras ha crecido en los últimos años, sólo en $9^{13}$ países ellas ocupan más del $20 \%$ de los cargos de Embajador, entre los que no se encuentra Argentina ${ }^{14}$. Al igual que en otros ámbitos del espacio público, la política y las Relaciones Internacionales están marcadas por la percepción de que lo masculino corresponde a lo público y, por lo tanto, al Estado, mientras el ámbito en que se desarrollan las mujeres es lo privado, invisibilizando su papel social y económico; como lo prueba la desigual presencia femenina existente en la diplomacia internacional, indicador de la persistencia de este patrón hegemónico masculino.

Si se trata de repensar a las mujeres como sujetos históricos, debemos velar por la incorporación de las mujeres en los espacios de formación de las futuras diplomáticas como el caso del ISEN en Argentina y principalmente generar una presencia activa en los altos escalafones de la alta diplomacia y en las representaciones en el exterior.

Para avanzar en el análisis de la posglobalización, es insoslayable lo escrito por el Papa Francisco en la encíclica Laudato SI (2015), cuando aborda en su mensaje la necesidad de revisar los paradigmas de la globalización, paz y seguridad. En el capítulo tercero, punto II llamado "Globalización del paradigma tecnocrático", señala que el problema fundamental reside en

el modo en como la humanidad de hecho ha asumido la tecnología....Por ello el ser humano y las cosas han dejado de tenderse amigablemente la mano para pasar a estar enfrentados. De aquí pasa fácilmente a la idea de un crecimiento infinito o ilimitado, que ha entusiasmado tanto a economistas, financistas, tecnólogos. Supone la mentira de la disponibilidad infinita de los bienes del planeta, que lleva a estrujarlo hasta el límite y más allá del límite.

La globalización se hizo tecnocrática y deshumanizada, dice. Y advierte que estrujamos el planeta más allá de sus límites, incluidos los ciudadanos y sus Estados. Esto es un claro problema en las Relaciones Internacionales. Para corregirlo se debe trabajar en el plano del diagnóstico que hemos hecho, en el plano intelectual de la formulación de ideas insertas en

13Según el Instituto universitario de Estudios de Género de la Universidad Carlos III de Madrid, en Estados Unidos tres de cada diez diplomáticos de máxima jerarquía son mujeres. También son casi el $30 \%$ en el caso del Reino Unido donde del total de 152 jefes residentes de misiones diplomáticas 46 son mujeres. En Israel dos de cada diez embajadores o cónsules tienen nombre de mujer.

14 Según datos del Instituto del Servicio Exterior de la Nación ( ISEN) , solo el $11.8 \%$ de las mujeres del Cuerpo Diplomático Argentino tienen rango de Embajador. 
la comunidad y el mundo, y en los formatos de ejecución de las ideas, para concretar beneficios directos de mejoras en la sociedad y los pueblos. Si la globalización fue utilizada por un capitalismo tecnocrático, financiero y político que no elevó las metas de mejorar a las sociedades; es hora de comprender que la agenda acuciante de nuestro siglo obliga a rediseñar las relaciones internacionales, las decisiones en las políticas exteriores y la validez de quienes deben formular estas políticas. El mundo debe verse a sí mismo, cada Estado, cada país, cada sociedad. Estamos convencidos de la necesidad de estudiar y revisar para brindar elementos para una sociedad más justa y respetuosa de las soberanías y autonomías en las relaciones.

Sobre globalización, independencia y autonomías se expiden con claridad Roberto Rusell y Juan Gabriel Tokatlián (2010) cuando señalan que: "nuestro enfoque de la autonomía que hemos denominado relacional, se define y sustenta en la acción cooperativa con los otros; considera que los problemas y desafío que presenta el orden mundial, cada vez más interconectado e interdependiente, exigen de nuestros gobiernos políticas activas responsables y comprometidas a través de una mayor equidad, participación seguridad y gobernabilidad globales"; esta es una definición de autonomía que estimamos completa, autónoma e inserta en el mundo real.

Entonces, se debe comprender que es momento de formular una política exterior, en tanto admitimos que la autonomía nacional dependerá también en gran medida de nuestras capacidades de inserción e intereses nacionales y estratégicos. La política y la diplomacia buscan el mismo objetivo: la paz mundial. Estos otros valores será plausible que aparezcan en la superficie y por encima de los individualismos que rigen en este tecnológico y tecnocrático siglo.

Las Relaciones Internacionales son naturales a la historia del hombre y los Estados. La Política exterior es la estrategia para la inserción del estado en la comunidad internacional y la defensa de sus intereses nacionales. La diplomacia es una herramienta de ejecución. Desde cada Estado se debe atender a la mejor selección y capacitación de los ejecutores de su política exterior. Cada Estado deberá indicar a su diplomacia los lineamientos, instrucciones y recomendaciones para las políticas y lineamientos que deban aplicar todos aquellos funcionarios y dirigentes que participan de la política exterior.

La formulación de la política exterior le corresponde directamente a los centros y grupos de pensamiento y elaboración, a los think-tanks: centros de estudio, foros de reflexión, academias, universidades y centros de pensamiento político, los que deben formular y diseñar la política exterior. Como sucede en el mundo contemporáneo los think tanks -grupo intelectuales de pensamiento- deben realizar esta tarea. De ellos saldrán productos para que el mandamás de cada Estado obtenga así las mejores recomendaciones y políticas objetivas e institucionales de Estado. Ello no significa que un funcionario de la vida pública, profesional de las Relaciones Internacionales o diplomático, no pueda elaborar y formular ideas de política exterior. Entendemos que es tiempo de que los académicos, investigadores y científicos dedicados a las Ciencias Sociales asuman esta responsabilidad primaria de pensar formulaciones y diseños para la política exterior conveniente a un país. 


\section{Dimensiones políticas y sociales para la formulación de una política ex- terior.}

Como hemos señalado al inicio, el mejor diagnóstico situacional nos brindará múltiples ventajas para pensar en formulaciones de una política exterior, en acuerdo con los contenidos políticos y sociales que demandan los tiempos contemporáneos.

Analicemos entonces algunos hitos políticos y sociales relevantes que van a condicionar la formulación de una política exterior, a saber:

\section{i. El siglo XXI es el siglo de la posglobalización y del posmodernismo}

Esta posglobalización y desorden afecta directamente a la formulación de una nueva política exterior y obliga a pensadores y ejecutores a comprometerse en el estudio de una agenda nacional acorde al actual orden. Las Naciones Unidas continúan bajo cuestionamientos en esta centuria, a partir del desdibujo del principio de la cooperación internacional. Deben seguirse atentamente los lineamientos que surgen del G7, el G 20 y la OMC, pues emanan de los países que concentran la riqueza e industria mundial. Las pandemias no detienen las economías, como se piensa. Detienen al mundo financiero, pero los cultivos e industrias continúan su curso; no debemos caer en ilusiones ni espejismos pasajeros al analizar el orden mundial y las potencias mandantes.

Debemos ser parte del conjunto de países que buscan la restauración de la cooperación internacional y la solidaridad por encima del equilibrio de poder, a partir de la comprensión de que esta posmodernidad debe considerar la fragmentación y la exaltación de las minorías. Los grupos relegados en el discurso de la modernidad resurgen en la posmodernidad. La filosofía oriental, el feminismo, los grupos con diferentes orientaciones sexuales y los pueblos originarios tienen algo que decir respecto a los problemas recurrentes de la sociedad. Los principales pensadores posmodernos (Vattimo, Lyotard, Rorty) y tardomodernos (Foucault, Derrida, Bataille, Baudrillard, Deleuze, Negri, Touraine) focalizan su análisis en los temas centrales del posmodernismo, como el fin de la historia, la crítica del humanismo, la política de la resistencia y la crítica del mundo de los medios masivos de comunicación.

La postglobalización y la posmodernidad afectan la guerra y la paz. Los conflictos han variado en forma y contenido. No olvidemos que se ha conformado un nuevo tipo de guerra permanente, silenciosa, hartera y tecnológica. Ello ha generado la necesidad de abordar los conflictos con alta tecnología y abarcar todos los conflictos que se puedan visualizar: conflictos internacionales, nacionales o de acciones de terrorismo fundamentalista, ideológicos, étnicos, religiosos, de frontera y civiles. Con armamentos clásicos, desarrollados y hasta sin armamentos.

\section{ii. Una nueva agenda mundial condiciona la formulación de la política exte- rior.}

Nuestro país y sociedad demandan participar en esta agenda marcada por la posglobalización y modernidad. En este sentido debemos perseguir que se prioricen las cuestiones 
sobre ecología integral, medioambiente y cambio climático, economías verdes, asuntos de seguridad internacional y desarme, programas sociales para mayor institucionalidad del Estado, programas sociales para mejoramiento de la distribución de riquezas y justicia, como así también compromisos para el desarrollo de la soberanía alimentaria.

\section{iii. La formulación de la política exterior debe pensarse y proponerse desde los centros o grupos de pensamiento, Think Tanks.}

Para comprender las vinculaciones entre política nacional e internacional que marcan el paso de las políticas exteriores desde un punto de vista aggiornado y crítico, merecen compilarse investigaciones y trabajos académicos que provengan de las Ciencias Sociales. Desde su espíritu, se pueden explicar el derrotero de las Relaciones Internacionales y su peculiaridad en cuanto a la naturaleza humana y social del hombre, a su conflictividad tribal y comunitaria, al nacimiento de los Estados, a las relaciones bilaterales de antaño y al desarrollo moderno de las relaciones multilaterales, orgánicas y también informales del siglo XXI. El contexto mundial y nacional plantea desafíos científico-tecnológicos, económicos y sociales que han promovido un cambio de cultura y mentalidad en directivos, profesores e investigadores universitarios hacia una investigación orientada a la tecnología, la empresa y la sociedad. Se parte de la agenda de la formación en Ciencias Sociales vinculada con la importancia del conocimiento, la calidad y la responsabilidad social universitaria; así como de la necesidad de nuevos paradigmas para comprender y asumir la complejidad de las problemáticas globales y locales.

\section{iv. La política exterior incorpora a los fenómenos migratorios y el problema de los refugiados en las agendas nacionales}

Este fenómeno en la agenda estratégica implica necesarios análisis de potenciales inseguridades y peligro. Son parte de la agenda de seguridad internacional y de los problemas nacionales de espacio, alimentos, salud y seguridad pública. Naciones Unidas reconoce el fenómeno y apela a su mejoramiento, consciente que está ligado a la hambruna, las guerras, los problemas de salud y los cambios climáticos profundos, aunque de manera insuficiente. Europa recobra la conciencia de esta problemática, pero también su accionar es condicionado e insuficiente hasta el momento, aún demasiado ligado a su historia colonialista. Latinoamérica no lo visualiza como un problema de gravedad, pero ello no significa que la problemática no exista. Simplemente no causa las discriminaciones, rechazos y conflictos laborales que sí causa en los países más ricos. Debemos incorporar la cuestión en la agenda de política exterior. El Mercosur puede proponer soluciones políticas, económicas y sociales en la materia. Es importante, ante problemáticas como las pandemias y endemias, tener protocolos claros y acuerdos internacionales que determinen los límites y alcances de nuestro cielo y fronteras abiertas.

\section{v. La política exterior requiere considerar en la formulación el alto valor de la democracia como régimen político y como régimen de vida.}

Argentina tiene la ventaja de no pertenecer de manera particular al club de países de guerra permanente y terrorismo internacional extremo. Esto, en principio; pues aún quedan 
importantes rémoras al recordar y considerar de los atentados a la Embajada de Israel y la Amia, que definitivamente afectaron la dimensión política social interna e internacional.

Si bien Argentina es un país joven, en ciertas materias es un país altamente maduro. Sufrimos en el siglo XX duros golpes de Estado y procesos de dictadura militar. En los años setenta asistimos a enfrentamientos políticos y armados de derechas e izquierdas ideologizadas en niveles internos e internacionales. Las guerrillas hicieron suya la bandera de la violencia y atacaron al estado, sus instituciones y, en particular, las fuerzas armadas y de seguridad. La represión del Estado fue inconmensurable. Los miles de desaparecidos fueron una causa nacional con repercusiones mundiales. El país consumió largos años, entre 1976 y 1983, resistiendo a armados constitucionales e institucionales hasta llegar a la salida democrática electoral, que permitió avanzar en reinstaurar la institucionalidad de manera gradual.

En la vuelta la democracia de 1983, los ejemplares juicios a las fuerzas armadas responsables e institucionales, y el abrazo que la sociedad civil realizó a las causas de los derechos humanos derivaron en un país que se reencausó gradualmente a sus instituciones. Los hechos ligados a la violencia en su historia política interna e imagen internacional hicieron al país conquistar la dimensión política y social de la defensa de los derechos humanos. Este valor desfiló desde entonces por el continente, el mundo, los organismos internacionales y diversas ONGs y foros mundiales, lo cual sigue vigente. Así se permitió asumir en la agenda de política exterior la causa de los Derechos Humanos. Las palabras "democracia” y "derechos humanos" comenzaron a tener institucionalidad y dimensión social más a partir de su inclusión en letra escrita en la reforma constitucional del Congreso Convencional de Santa Fe en 1994.

\section{vi. La formulación de política exterior debe siempre priorizar el valor de la in- tegración regional.}

Sobre ello hemos ya referido el marcado e histórico espíritu de integración regional del sur de América Latina. Son razones políticas, institucionales, económicas y culturales que impulsan a una mayor integración, más allá de caudillajes nacionalistas o autonómicos.

La alianza surgió por la voluntad de Brasil y Argentina, para que pueda consolidarse y volver a convertirse en un eje estratégico fundamental que beneficie directamente el crecimiento de nuestros pueblos y mejore la inserción de ambos países en el mundo. El Mercosur tiene todos los elementos para colaborar en esta tarea. Nos queda pendiente repensar las alianzas subregionales que nos permitan reforzar una comunidad sudamericana, tantas veces soñada en las comunidades nacionales, aún separadas por fronteras pasaportes y miles de estigmas nacionalistas autonomistas en Sudamérica. No hay inserción internacional pretendida alguna, ni inteligente o práctica, que se contradiga con los mandatos integracionistas que desarrolla el continente, cuyo mejor ejemplo es el Mercosur.

\section{vii. La formulación de política exterior debe incluir una agenda de derechos hu- manos y una agenda de género.}

Hemos visto las razones y la dimensión política y social que debe comprender la formulación a realizar. Los derechos de género y de la mujer en la vida política y social son una 
avanzada ejemplar en Occidente. Aunque sepamos que el planeta convive aún con anacrónicos retrasos en la materia y dictaduras que no favorecen derechos ni de género ni humanos en general; debe devenir en prioridad la formulación de las políticas públicas con consenso interno y externo. "[L]a lucha política, las disputas, el derecho de piso, la capacidad de negociación, la confrontación, son parte de la realidad del mundo político que incomoda a estas recién llegadas, por alejarse de la naturaleza en que se fueron construyendo como sujetos sociales (...) les otorga seguridad y las legitima", y grafican con claridad este avance de la mujer en el mundo político varonil (Colotta, 2014).

Más allá de las estadísticas poco alentadoras y los claroscuros en un ámbito que históricamente ha sido patriarcal, la creación de direcciones y ámbitos en la administración pública que impongan temas de agenda y promuevan la intervención en la elaboración de planes, programas, proyectos operativos y cursos de acción para los eventos internacionales relativos a cuestiones de género y la igualdad de oportunidades, empoderan a las mujeres, que han sorteado dificultades y han impuesto sus liderazgos legítimamente, e invita a las jóvenes generaciones a replantear el espacio público y asumir nuevos roles como autoridad. Tal es la propuesta desde la Cancillería Argentina (2020) parae la creación de la Dirección de la Mujer y Asuntos de Género, legitimando y jerarquizando un espacio propio dentro del Ministerio más allá de la órbita de la Dirección de Derechos Humanos. Estratégicamente buscará esta nueva área: la participación en las relaciones con los demás Estados en los temas vinculados a los asuntos de género y sus regímenes legales internacionales; la intervención en la elaboración de planes, programas, proyectos operativos y cursos de acción para los eventos internacionales relativos a cuestiones de género y la igualdad de oportunidades; y será la encargada de "propiciar los estudios, el diseño y la evaluación de dichos proyectos, programas y planes con los otros organismos y dependencias del Estado nacional que sean relevantes para la política exterior" (Cancillería, 2020). Otra de las acciones que llevará a cabo será la de "participar en el estudio de la normativa de derecho interno para su adecuación a las normas del derecho internacional sobre la condición de la mujer y temas de género" y también "la participación en la conclusión de tratados, acuerdos y convenios internacionales que en materia de la situación de la mujer y temas de género, sea parte del país" (Ibid.).

\section{viii. La política exterior debe formularse con agendas de tecnología}

La tecnología aplicada a los conflictos en el mundo es solo una variante que obliga a su seguimiento e incorporación en toda agenda de política exterior. La tecnología que se aplica a las agendas de guerra y las agendas de diplomacia para la paz, así como la diplomacia a través de la tecnología incorporó los pilares del comercio internacional y se introdujo en las tareas y funciones de los bancos y carteras públicas y empresariales que debían ordenarse e institucionalizarse; no cabe duda de que el diplomático se mostró a la altura de estos nuevos desafíos. Hoy hablamos de Embajadores 2.0, porque los mismos profesionales y expertos no pueden encabezar relaciones o delegaciones o negociaciones si no están al tanto de lo que la tecnología le brinda como beneficios y, en gran medida, como ventajas. El sistema comunicacional e informativo de un diplomático ha revolucionado las relaciones internacionales. Es también la tecnología y la informática y la velocidad comunicacional la que 
ha permitido a la diplomacia y las relaciones internacionales, incorporar de manera sustantiva, directa, en cumbres y formatos ad hoc, agendas de negociación y oportunidades económico-comerciales.

\section{ix. La política exterior debe formularse con prioridad de políticas de promoción comercial}

En la formulación de una política exterior ocupan un lugar primordial las políticas comerciales y de relaciones económicas internacionales. La Secretaria de Relaciones Económicas Internacionales y la Fundación Exportar, que el Gobierno de Cambiemos transfirió al Ministerio de Producción y diluyó en recursos y objetivos, no alcanzaron para eliminar la necesidad imperiosa de incorporar y consolidar las políticas de promoción y la inteligencia comercial ligada a las inversiones. Al volver en 2019 la Agencia de Comercio o Fundación a la Cancillería, existe la oportunidad de que estos instrumentos recuperen toda su fuerza y expansión en la política de promoción e inteligencia comercial, que son de la naturaleza propia de la política exterior.

Podemos pensar en la planificación de un Consejo público-privado a tal efecto y un adecuado trabajo de inteligencia y promoción comercial por parte de la Cancillería, de la Agencia, de las Embajadas y de los Centros de promoción comercial en el exterior. Todo ello, en favor del empresariado, del comercio y la activación de las inversiones internacionales.

En los que hace al relacionamiento económico multilateral, además, la Cancillería puede diseñar nuevamente políticas, las cuales -a partir de sus expertos profesionales- trabajen y negocien con presencia ante diversos organismos económicos-comerciales. Los Los tribunales comerciales no son para novatos o improvisados sino para diplomáticos y profesionales expertos en la materia, que nuestro Estado debe capacitar siempre. Los conflictos en paneles afectan a nuestro país, provincias, municipios y pueblos. Tienen correlación con innumerables problemas derivados de las economías regionales y la producción económica ligada al comercio exterior.

Un presupuesto de esta política de promoción de oportunidades e inversiones es que la política económico-financiera y la política exterior estén en vínculo directo y armónico con la política interna. La tarea de formular una política exterior sería más sencilla si se promueve un diálogo correcto y digno con los foros acreedores de Argentina, si se propende al seguimiento de políticas ordenadas ante el FMI y acreedores externos, es decir, una política de responsabilidad fiscal con consensos ciertos sobre la necesidad del combate a la inflación.

La formulación de la política exterior debe considerar que las políticas de promoción comercial incorporen la agenda federal de la Argentina: una diplomacia federal hacia provincias y municipios que se transmita en lo económico y comercial, y en el mapa de las economías regionales.

\section{x. La formulación de la política exterior debe considerar que toda política exterior es generadora de empleo.}

Cuando el servicio exterior puede desplegar una adecuada diplomacia de promoción comercial e inversiones, a través de negociaciones y misiones, sus efectos de inserción e 
intercambio se convierten en una herramienta que, en plazo inmediato, redunda en ingresos y genera empleo en el país.

\section{xi. La formulación de la política exterior debe desterrar el pensamiento aisla- cionista}

El aislacionismo practicado en nuestra política exterior no ha sido la constante de nuestra historia, pero sí un elemento que nos ha condicionado a actuar con políticas constantes ante el mundo. Y nos ha limitado al no permitir reflexionar sobre diagnósticos correctos y, por tanto, perjudicar la formulación de una política exterior con prioridades y a la medida del país y las necesidades de su sociedad. No existe ninguna constante aislacionista consolidada en nuestra política internacional pasada ni presente. Ojalá así fuera. Tampoco existen determinantes como el aislacionismo, el jurisdiccionismo, el moralismo o la vocación de renuncia a la territorialidad.

Estos condicionantes de una escuela de los 60 y 70 marcaron de manera confusa nuestra política exterior en el pasado siglo, pero los estudiosos y formuladores de política exterior que aparecieron con fuerza desde la llegada de la democracia en 1983 lograron superar este principismo idealista, heredado de esquemas de política exterior argentina doctrinario que simplificaba nuestra realidad nacional e internacional.

En definitiva, el aislacionismo ha si sido un factor menor en la historia de nuestra política exterior, aunque amenazara ser a veces desestabilizante, incluso en los casos históricos de conflictos civiles o la desgraciada guerra de Malvinas, que aún sufrimos por ser una causa nacional primaria de nuestro pueblo. Pero ello obligó a las dirigencias y profesionales a corregir los rumbos de reinserción en favor de una integración armoniosa y conveniente a los intereses nacionales.

\section{xii. La formulación de política exterior requiere de prioridades y alianzas estra- tégicas:}

Las alianzas especiales han sido, en épocas democráticas, alianzas con aliados históricos naturales, como Italia y España, y otras apuntadas al seguimiento de formatos de potencias como Alemania y Japón. Este concepto, que algunos resultados puede brindar positivamente, es un concepto de negociación superado. Las alianzas especiales válidas en sus convenios y relacionamiento en general, han sido superadas por las llamadas alianzas estratégicas.

En la formulación de la política debemos pensar siempre cómo formular preferencias o círculos estratégicos.

El primer círculo es siempre Brasil y nuestra región, el Mercosur. Un segundo círculo es el virtuoso occidental a través de Europa y el norte de América. Un tercer círculo de potencias que negocian con políticas comerciales sólidas los constituyen China y Rusia. Un cuarto círculo virtuoso es el que más éxitos comerciales pueden generar a nuestra política exterior, pues es el que abarca los Nuevos Mercados en Asia, Medio Oriente y el Africa, un círculo central especial por su globalidad lo ocupan en la formulación de la política exterior 
la relación con el sistema multilateral y la cuestión de Malvinas, hito nacional determinante en nuestra política exterior nacional.

\section{Reflexiones finales}

La tarea de formulación de política exterior es una tarea intelectual y pragmática. La dimensión política y social condiciona la tarea. Debe considerarse el nivel de cohesión social para avanzar en consensos que son aplicables a la política internacional.

La formulación implica determinar las prioridades que necesita la Argentina en materia de política exterior y que le permitan al país -gobierno y sociedad-redefinir en aserciones los verdaderos "intereses nacionales" en juego. Entre estas prioridades incluimos la univocidad de la diplomacia, la diplomacia comercial empresarial y de inversiones, las ventajas de una mayor presencia y espíritu multilateral, la incorporación de estrategias para la diplomacia directa y de cumbres, y la aplicación diplomacia pública.

Hemos expuesto sobre la dimensión política y social que condiciona la formulación de la política exterior, y queremos además volcar conclusiones. Finalmente, nos debemos la tarea de destacar aquellos principios que estimamos deben tomarse en cuenta en los mecanismos de ejecución de la política exterior, a saber:

1. La política interna y la diplomacia mantienen un vínculo indisoluble, y el aporte intelectual académico político y de la sociedad civil actúan de manera directa sobre la formulación de una política exterior.

2. La política exterior debe asumir como propia la defensa del sistema republicano y todas sus instituciones, su esquema presidencial y división de poderes. La defensa de la República y la Democracia son parte misma de nuestras marcas ante el mundo contemporáneo.

3. La política exterior la dicta y conduce el Poder Ejecutivo Nacional y en ello colaboran los demás poderes del Estado. Por lo tanto, la diplomacia pública y la prensa se deben canalizar de manera centralizada en lo que hace a política internacional.

4. La política siempre debe priorizar la búsqueda de una mayor inserción internacional y evitar todo tipo de nacionalismo aislacionista en el pensamiento exterior.

5. La política exterior debe apoyarse principalmente en la diplomacia profesional, de larga tradición de expertos formados para atender las relaciones bilaterales y las agendas multilaterales complejas, que requieren más capacitación profesional cada día.

6. La formulación de la política exterior la deben elaborar y sistematizar think tanks, académicos, consejos profesionales, políticos dedicados a la materia, centros de estudio y unidades o fundaciones académicas de prestigio.

7. La formulación de la política exterior significa realismo y practicismo en los objetivos estrategias y resultados o beneficios logrados. El practicismo constituye una aserción a considerar para formular política exterior: practicismo en las estrategias; practicismo en las alianzas; practicismo en las políticas comerciales, oportunidades de inteligencia 
comercial y apoyo a la diplomacia empresarial; practicismo en la conformación orgánico profesional de una Cancillería; practicismo en la determinación de los recursos humanos a aplicar; y practicismo en la elección de las características para asociaciones bilaterales, alianzas estratégicas y políticas multilaterales.

8. La formulación de la política exterior se debe realizar a partir de prioridades, urgencias, alianzas de mediano y largo plazo, y el establecimiento de una planificación de alianzas estratégicas especiales, a través de "círculos de prioridad", estableciendo con claridad la diferencia entre prioridades, alianzas de mediano y largo plazo, y urgencias.

9. La formulación de política exterior no puede contemplar empatías ideológicas o supuestamente amistosas. Ocurre que la mayoría de las veces las expresiones mediáticas mismas conllevan el objeto de la desinformación o la búsqueda de confrontaciones relativas a los líderes o sus pueblos. No existe en política exterior algo menos serio que creer que los países se unen o no porque sus líderes son "parecidos y empáticos, amigotes". Es una concepción naïve, peligrosa, ideológica y nada práctica, útil a los interese nacionales. $Y$ hace mucho daño al profesionalismo y al relacionamiento institucional externo.

10. La diplomacia profesional es la herramienta fundamental profesional y técnica para aplicar las órdenes de la política exterior. El Servicio Exterior Argentino cuenta con escasos recursos humanos, una alta tasa de eficiencia, un muy bajo presupuesto y una larga tradición de capacitación de casi 60 años. Supera con creces toda improvisación política.

11. La formulación de la política exterior ha de generar crecimiento a la Argentina. El día después de las pandemias, el día después de los acuerdos financieros con el FMI, el día después de la parálisis productiva, el día después, seguimos siendo un país de enorme superficie y potencial riqueza territorial y de recursos que debe insertar a la producción, su litio, su energía y litoral marítimo. Formular la política exterior comienza por entender que la misión de la diplomacia es vender la marca país, promover comercio e inversiones, y en definitiva siempre generar más empleo.

La diplomacia es un instrumento de diálogo y paz. Así nació y es su naturaleza propia. Sólo en el caso de los Estados que piensan a extensos plazos en la política internacional, se comprende del todo esta premisa. Nuestro país puede crecer, además, desde la formulación de políticas públicas de orden interno y externo que fomenten el diálogo y la paz con objetivos de cooperación y solidaridad

\section{Bibliografía}

Aranda R A (2004), La política exterior argentina de Menem a Kirchner, Buenos Aires: Ed. IRI. UNLP.

Beligh A \& Vanhulst A (2019), Desarrollo non sancto, México: Ed. Siglo XXI.

Botto. M (2015), La integración regional en América latina ¿quo vadis?, Buenos Aires: Ed. Eudeba. 
Bouzas R \& Pagnotta (2003), Dilemas de la política comercial exterior argentina, Buenos Aires: Ed. Siglo XXI.

Calduch Cervera R (1993), Dinámica de la sociedad internacional, Madrid: Ed. Universitaria Ramón Areces.

Cancillería (2020), Comunicado de prensa 048/20. Recuperado de: https://cancilleria.gob.ar/es/actualidad/noticias/sola-anuncio-la-creacion-de-la-direccion-dela-mujer-y-asuntos-de-genero. Viernes 6 de marzo de 2020.

Cavarozzi M (2006), Autoritarismo y democracia 1955-2006, Buenos Aires: Ed. Ariel.

Cavarozzi M (2014), La construcción política de las sociedades latinoamericanas y su talón de Aquiles: el régimen político, Rosario: Ed. Cuadernos de Ciesal. Año 11.

Cisneros A \& Piñeiro Iñiguez C (2002) Del ABC al Mercosur, Buenos Aires: Ed. Nuevo Hacer Gel.

Colotta M \& Lascano y Vedia JR (2020), Contrapuntos para comprender las relaciones internacionales en el siglo XXI. Un análisis crítico de la política internacional, Buenos Aires: Ed. Teseo.

Colotta M y otros (2019), Políticas universitarias para el siglo XXI. Perspectivas y temas de Agenda, Buenos Aires: Ed.Teseo.

Colotta M (2014), La ¿nueva? Inclusión de las mujeres al mundo político. Los discursos y prácticas de las concejales bonaerenses, 2da Edición, Buenos Aires: Ed. Biblos.

Columbus T \& Wolfe J (1979), Introducción a las relaciones internacionales, Buenos Aires: Ed. Troquel.

Escude C (2003), Historia general de las relaciones exteriores de la República Argentina, parte IV, 1989-2000, Buenos Aires: Ed. Nuevo Hacer, GEL.

Fernandez de Kirchner C (2019), Una política exterior soberana, Buenos Aires: Ed. Colihue.

Kissinger H (2017), La diplomacia, México: Ed. Fondo de Cultura Económica.

Kissinger H. (2016), Orden mundial, Buenos Aires: Ed. Debate.

Laclau E. (2005), La razón populista, Buenos Aires: Ed. Fondo de Cultura Económica.

Lanús JC (1984), De Chapultepec al Beagle 1945-1980, Buenos Aires: Ed. Emece.

Lascano y Vedia JR (2020), Hacia una nueva diplomacia: Ideas para el diseño de una política exterior, Buenos Aires: Ed. Biblos .

Lascano y Vedia JR (2009), Política y diplomacia: una política institucional hacia el mundo, Buenos Aires: Ed. Tu llave.

Lerena C (2019), Atlántico Sud, Malvinas y reforma federal pesquera, Mar del Plata: Ed Impronta.

Mestre Vives T (1979), Política internacional como política de poder, Barcelona: Ed. Labor. Methol Ferré A (2013), Los estados continentales y el Mercosur, Montevideo: Ed. Hum. Miguez MC (2011), La política exterior 2002-2005: nuevos aliados y socios y el dilema de la 
autonomía, Buenos Aires: Ed. Octubre.

Miguez MC (2013), Los partidos políticos y la política exterior argentina, Buenos Aires: Ed. Ariel. Morgenfeld L (2011), Relaciones peligrosas, Argentina y Estados Unidos, Buenos Aires: Ed. Capital Intelectual.

Mussachio A, Crivelli A \& Miguez MC (2006), El Mercosur en cuestión: Integración económica e inserción internacional, Buenos Aires: Ed. Cooperativas.

Pasquino, G (2011), Nuevo Curso de ciencia Política, México: Ed. Fondo Cultura Económica.

Puig JC (1984), América Latina políticas exteriores comparadas, Buenos Aires: Ed GEL.

Rapoport M (2016), Historia oral de la política exterior 1966-2016, Buenos Aires: Ed. Octubre.

Rapoport M (2019), Política internacional argentina, Buenos Aires: Ed. Capital Intelectual.

Russel R \& Tokatlián J G (2003), El lugar de Brasil en la política exterior argentina, Buenos Aires: Ed. Fondo de Cultura Económica.

Romero A (2020), La cuestión Malvinas Una hoja de ruta, Buenos Aires: Ed. Eudeba.

Rouquié A (2017), El siglo de Perón. Ensayo sobre las democracias hegemónicas, Buenos Aires: Ed. Edhasa.

Rusell R \&Tokatlian JG (2010), Autonomía, neutralidad y globalización, Buenos Aires: Ed. Capital Intelectual.

Russel R \& otros (1992), La política exterior argentina en el nuevo orden mundial, Buenos Aires: Ed Gel.

Sanchiz Muñoz J (2010), Historia diplomática argentina, Buenos Aires: Ed. Eudeba.

Simonoff A (2016), El aporte de la escuela socio histórica en Las Relaciones Internacionales, Buenos Aires: Ed. Octubre.

Sorj B \& Martuccelli D (2008) El desafío latinoamericano. Buenos Aires: Ed. siglo XXI.

Spanier J (1991), Política exterior de norteamericana da partir de la segunda guerra mundial, Buenos Aires: Ed. Grupo Editor Latinoamericano.

Stiglitz J (2002), El malestar de la globalización, Estados Unidos: Edit. WW Norton \& Company.

Stiglitz J (2006), Como hacer que funcione la globalización, Estados Unidos: Edit.WW Norton \& Company. 